\title{
Rose Water Distillation
}

Milja Helenius

Unit of Chemistry Teacher Education, Department of Chemistry, University of Helsinki, Finland • milja.helenius@helsinki.fi

\section{Maija Aksela}

Unit of Chemistry Teacher Education, Department of Chemistry, University of Helsinki, Finland • maija.aksela@helsinki.fi

\section{Anu Hopia}

Functional Foods Forum, University of Turku, Finland • anu.hopia@gmail.com

\section{Erik Fooladi}

Volda University College \& Norwegian Centre for Science Education, Norway • ef@hivolda.no

\begin{abstract}
Steam distillation has been used for over two thousand years to isolate the scent of flowers. Rose water is nowadays a rather uncommon ingredient in European cuisine but it is common in, for example, Arabic recipes. The quality of flower distilled waters has improved due to advances in distillation techniques, allowing for better salvaging of flavourings. The aim of this work is to use two different kinds of distillation equipment, modern laboratory distillation equipment and homemade kitchen equipment, and to compare the scents of distilled rose waters. The work is suitable for teaching chemistry in upper secondary school and, if simplified slightly, in secondary school as well.
\end{abstract}

\section{The aim of the workshop}

The aim of our workshop is to provide teachers with new ideas on how to combine chemistry and molecular gastronomy in teaching. If this work is used in a school, the aim is for the students to learn how to use distillation equipment and to understand how it works. The work also deals with solubility and boiling point. The work is suited especially well for the first chemistry course (KE1 chemistry of human and environment) in upper secondary school as the aim of the course is for the students to learn how to study features and reactions of organic substances through experiments, and to familiarise themselves with differentiation- and identification methods (Finnish National Board of Education, 2003). The work is suitable for secondary school as well, but it is suggested in this case to use simpler equipment.

\section{The realisation of the work}

The work is performed according to the instruction "Ruusuveden tislaus kotikeittiössä" (Hopia, 2008) with kitchen utensils, and also with laboratory distillation equipment for comparison.

Ingredients:

- rose petals 
If the rose water is going to be tasted or used in cooking the roses have to be freshly picked from a clean environment; roses from a florist's or treated with biocide will not do. Remove the petals and rinse them in mild salt water. Then put them under ice cold water.

\subsection{Distillation with laboratory equipment}

Instruments:

- distillation equipment with a water condenser

Instructions:

1. Cut the petals into strips and place them in a distillation flask with water.

2. Turn on the condenser and heat the flask at mild temperature.

3. Gather the distillate into a receiving flask. The first three fractions are collected and the receiving flask changed every sixth minute. This is done for two reasons. Different compounds may have different boiling points in which case the more vaporisable distils first. This may have an effect in laboratory equipment distillation but likely not in kitchen equipment distillation. In addition, the scent of the rose may change due to temperature and some compounds may go through chemical changes.

\subsection{Distillation with kitchen equipment}

Instruments:

- a large steel pot with a lid and a configuration built at its base which allows the distillate receiving cup to be placed above water surface in the center of the pot; flat-bottomed ceramic or stone cup turned upside down or a square tile is fine;

- a small cup is also needed for collecting the distillate and

- some ice is needed for the cooling.

Workstages:

1. Fill a quarter of the pot with water.

2. Place the distillate receiving cup at the centre of the pot on the configuration so that the receiving cup is not in water.

3. Cut the petals to strips and place them in the water.

4. Put the lid on its place upside down. If the lid has a handle in the middle it acts as a good collector for the liquid from which the distillate drops directly into the receiving cup (Figure 1).

5. Bring the water to boil. When the water starts to boil fill the lid of the pot with crushed ice. This keeps the lid cool and the vaporising liquid is effectively condensed on the lid's inner surface, from where it drips into the receiving cup.

6. Let the liquid simmer at a mild temperature. Collect distillate from the receiving cup at even intervals with, for example, a syringe or a pipette.

7. Gather distillate three times into different bottles at six minute intervals. 


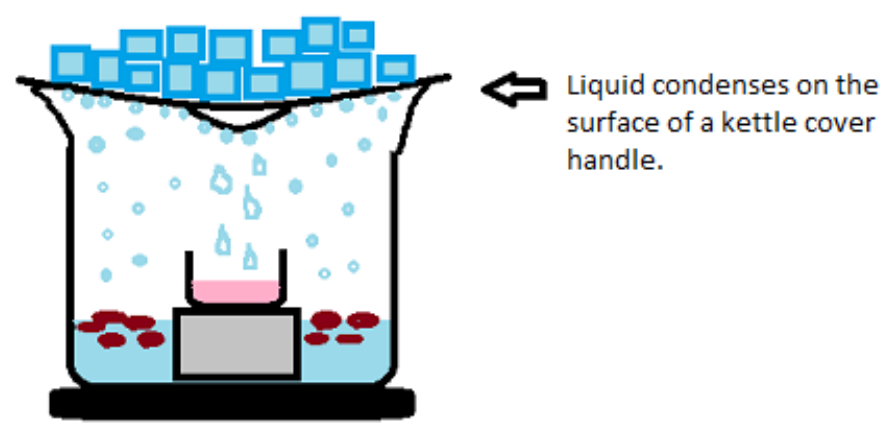

Figure 1. Rose water distillation with kitchen equipment.

\subsection{Comparison between the distillates}

One person marks the received distillates for example on the bottom of the bottles so that he himself knows which distillate comes from which equipment and fraction. For example, A1, A2, A3, B1, B2, B3. Next, couple drops of distillate are applied to filter paper slips and the scents are analysed so that only the person handling the bottles knows which scent comes from which bottle.

The following can be assessed: 1) Is the scent fruity or rosy? 2) Are there differences in the scents? 3) Which scent is the most intense? The purpose is to describe the scents with objective descriptions and to avoid subjective opinions of pleasantness or unpleasantness. The assessments are written down after which there is a discussion on which scent comes from which bottle and why. In the end, the person handling the bottles reveals where the scents come from.

\section{Theory for the work}

\subsection{History of distillation}

Alchemists developed the first distillation equipment in the 1st century $\mathrm{AD}$ in Alexandria. Early on the only equipment was the container "bikos" and the dome "ambix" where the steam rising from the container was condensed. To heat the container different kinds of ovens and sand- and water baths were used. Since the alchemists did not yet have access to water condensers the method they used was quite ineffective (Hudson, 2002).

Arab alchemists learned the distillation process from the Alexandrians in the Middle Ages and developed it further. In the 10th century, Avicenna, the last notable writer of alchemy in the Islamic Golden Age invented a separate condensate hood for the distillation equipment that gathered the steam rising from the cooking pot into a separate container. This invention made the separation of substances and the gathering of flavourings from flower waters considerably more effective. (Hudson, 2002; Hopia, 2008) 
In the 12th century European scholars found Arabic writings that helped to develop the art of distillation in Europe. Europeans started to distil wines and were able to produce distillates so strong that they were flammable. Italian Taddeus Alderotti in the 13th century started to use a spiral cooling tube that was put under water in a bowl with cold water running into it. This first water condenser further improved the effectiveness of condensation and made it possible to produce flammable alcoholic solution, aqua ardenis, which could be distilled further to produce the water of life, aqua vitae. (Hudson, 2002)

\subsection{Basics of distillation}

Liquids that are mixed together and have a different boiling point can be separated through distillation. When the distillation flask is heated, the liquid with the lowest boiling point evaporates first. The steam rises to the top of the equipment and condenses in the condenser into drops, the distillate, that drip into the receiving flask. When the temperature is raised the liquid with the second lowest boiling point evaporates, and so on. By collecting distillates distilled in different temperatures to separate receiving flasks the different substances can be separated from each other.

\subsection{What happens in the distillation flask or the pot when distilling rose water?}

Flavourings and other water soluble compounds are extracted from the rose petals to hot water. The reaction is the same as the one in making tea or coffee, compounds dissolve in water. Thereafter, volatile compounds, such as water and flavourings extracted from the petals, evaporate in their respective boiling points. Non-volatile compounds usually cannot be distilled even if they were extracted to water. When evaporated substances touch a cold surface, such as the distillation equipment's condenser or the lid of the pot, they condense into drops and fall into the receiving container.

\subsection{Applications for rose water}

Rose water is widely used in the cuisine of the Middle East and Asia, especially in desserts and sweets. It can also be used in perfumes and scents.

If the rose water is made from edible roses with clean equipment it can be used, for example, in following ways:

- Add $1 / 2$ tea spoons of rose water in blueberry cupcake batter and glazing.

- Add 1-2 tea spoons into a litre of cold drink. 


\section{References}

Finnish National Board of Education. (2004). National core curriculum for comprehensive school 2004. Helsinki: Finnish National Board of Education.

Hopia, A. (2008). Kemiaa keittiössä. Helsinki: Nemo.

Hudson, J . (2002). Suurin tiede: Kemian historia (K. Pietiläinen, transl.). Helsinki: Art House. (Original published in 1992). 
HELENIUS ET AL. 